\title{
Sources of interannual yield variability in JULES-crop and implications for forcing with seasonal weather forecasts
}

\author{
K. E. Williams and P. D. Falloon \\ Met Office Hadley Centre, FitzRoy Road, Exeter, Devon EX1 3PB, UK \\ Correspondence to: K. Williams (karina.williams@metoffice.gov.uk)
}

Received: 28 April 2015 - Published in Geosci. Model Dev. Discuss.: 22 June 2015

Revised: 27 October 2015 - Accepted: 16 November 2015 - Published: 15 December 2015

\begin{abstract}
JULES-crop is a parametrisation of crops in the Joint UK Land Environment Simulator (JULES). We investigate the sources of the interannual variability in the modelled maize yield, using global runs driven by reanalysis data, with a view to understanding the impact of various approximations in the driving data and initialisation. The standard forcing data set for JULES consists of a combination of meteorological variables describing precipitation, radiation, temperature, pressure, specific humidity and wind, at subdaily time resolution. We find that the main characteristics of the modelled yield can be reproduced with a subset of these variables and using daily forcing, with internal disaggregation to the model time step. This has implications in particular for the use of the model with seasonal forcing data, which may not have been provided at subdaily resolution for all required driving variables. We also investigate the effect on annual yield of initialising the model with climatology on the sowing date. This approximation has the potential to considerably simplify the use of the model with seasonal forecasts, since obtaining observations or reanalysis output for all the initialisation variables required by JULES for the start date of the seasonal forecast would present significant practical challenges.
\end{abstract}

\section{Introduction}

The ability to forecast crop yield on a seasonal timescale has significant economic and humanitarian benefits (Hansen et al., 2006; Iizumi et al., 2014; Mishra et al., 2008). Climate variability and extremes can have significant impacts on crops (e.g. Challinor et al., 2014), and improvements in the seasonal forecast of meteorological variables such as temperature and rainfall (Molteni et al., 2011; MacLachlan et al., 2015; Manzanas et al., 2014) therefore have the potential to improve yield forecasts. However, existing studies of crop model performance focused on seasonal forecast applications show considerable variation in skill depending on the region, scale, processes and crops involved (Hansen et al., 2011; Dessai and Bruno Soares, 2013; Falloon et al., 2013). Crop model simulations driven by statistically downscaled seasonal hindcasts for European wheat (Palmer et al., 2004; Cantelaube and Terres, 2005), and specifically for wheat in Italy (Marletto et al., 2007), showed that reliable crop yield predictions could be produced using an ensemble multi-model approach and the Joint Research Centre (JRC) crop model, for instance, estimating a high probability of a positive yield anomaly in 1996 and a negative yield anomaly in 1998 in the UK, consistent with observations. Similarly, Coelho and Costa (2010) used an ensemble of bias-corrected and disaggregated seasonal forecasts to simulate maize yields over southern Brazil, with the General Large-Area Model for annual crops (GLAM) crop model. The model showed generally good agreement with observations, with observed yields within the $95 \%$ forecast interval for most years. Using a statistical approach to assess the reliability of hindcasts of global-scale yield decreases of at least $5 \%$, Iizumi et al. (2013) found that within-season hindcasts with lead times of 1-3 months generally reproduced interannual variability in observed yields in major wheat-exporting countries better than pre-season hindcasts with lead times of 3-5 months. Iizumi et al. (2014) modelled global yields of major crops by combining satellite-derived net primary productivity (NPP) data and global agricultural data sets for crop calendar, harvested area and country yield statistics. This statistical model mostly performed well compared to 
observations, with modelled yields explaining $45-81 \%$ of the spatial variation of observed yields in 2000 , and correlation coefficients between modelled yield time series and sub-national yield statistics for 1982-2006 in major cropproducing regions generally greater than 0.8 . Nicklin et al. (2011) found some positive skill in reproducing both severe crop failure (yields below 10th percentile of climatology) and less severe crop failure (yields below the 25th percentile of climatology) of groundnut in West Africa with GLAM driven by seasonal forecast data; they found that these results were relatively independent of assumptions on the varieties of groundnut modelled. Mishra et al. (2008) ran the Système d'Analyse Régional des Risques AgroclimatiquesHabillé (System for Regional Analysis of Agro-Climatic Risks) (SARRA-H) crop model at five locations in Burkina Faso, showing that, in most cases, incorporating seasonal rainfall forecasts improved sorghum yield predictions made early in the season.

Palmer et al. (2004) and Cantelaube and Terres (2005) also found that downscaling seasonal hindcasts improved crop model performance - the $r^{2}$ value of simulated biomass for the whole of Europe increased from 0.62 to 0.69 with greater regional improvements when downscaled seasonal forecasts were used instead of the original, pre-downscaled versions. On the other hand Challinor et al. (2005) found that bias correction of general circulation model (GCM)-derived seasonal hindcasts data had generally small effects for simulation of groundnut yields in India. Watson and Challinor (2013) found that errors in rainfall data had the largest impact on crop model skill for groundnut in India, mainly because the study region was rainfall limited, while generally the largest yield errors were caused by errors in interannual variability in temperature and precipitation. In contrast, for French maize, temperature errors had a stronger influence on yield estimates from both a statistical model and a processbased model than precipitation (Watson et al., 2014).

The ability of crop models to represent interannual effects of climate variables also varies depending on the processes represented in the models (Falloon et al., 2014b). For example, high-temperature stress around anthesis (the onset of flowering) can have strong impacts on crop yields, but not all models include this effect, and responses vary across models that do (Asseng et al., 2013). In general, there is little information on the role of initial conditions such as soil moisture in crop model performance on seasonal timescales (Falloon et al., 2013), although hydrological studies have shown that different spin-up approaches may be needed for different impacts (Cosgrove et al., 2003) and different regions.

The JULES-crop model (Osborne et al., 2015) was developed with the dual aim of being able to simulate the impact of weather and climate on crop productivity and the impact that croplands have on weather and climate. It is a component of the Joint UK Land Environment Simulator (JULES) (Best et al., 2011; Clark et al., 2011), which is a community land surface model that can be used both online as part of the
Met Office Unified Modelling system and offline for impact studies. As part of the EU FP7 project EUPORIAS (European Provision Of Regional Impacts Assessments on Seasonal and Decadal Timescales; Hewitt et al., 2013), JULEScrop will be driven by seasonal forecasts and its ability to produce probabilistic forecasts of crop yield will be investigated. EUPORIAS aims to maximise the societal benefit of seasonal and decadal forecasts by making the predictions directly relevant to decision makers. As part of this project, a multi-model ensemble of seasonal meteorological forecasts will be used to drive an ensemble of impacts models, including JULES-crop.

However, using JULES-crop on a seasonal timescale introduces a number of technical and scientific issues. The aim of this paper is to address those issues that are centred around the availability of data, by investigating to what extent the interannual variability of the modelled yield can be captured if some of these data requirements are relaxed.

The first data availability issue concerns the driving data. JULES is driven by a combination of meteorological variables describing air temperature, precipitation, radiation, wind speed, humidity and pressure (for a full description, see the JULES User Guide, available at https://jules.jchmr.org/) for each grid box in the model domain, ideally at subdaily resolution. Output in this format for each ensemble member requires a large amount of storage space and is typically not made externally available by seasonal forecast centres. It is therefore useful to investigate whether the yield variability can be modelled sufficiently well if only a subset of the forcing variables are taken from the seasonal forecast and the others set to climatology, or if the model is forced with daily meteorological data and disaggregated internally to the model time step. To gain a better understanding of the dependence of the yield on the different forcing variables, we look at the effect of removing water stress and the correlation of the yield with the total grid box precipitation during the crop-growing season.

The second data availability issue concerns the variables required to initialise the JULES-crop runs, such as the moisture content of each soil layer (as a fraction of the water content at saturation). Obtaining accurate values for these variables on the start date of the seasonal forecast runs would present a significant practical challenge, as recent observations would be required to estimate these values directly or as input to a reanalysis run. Therefore, we investigate the loss in predictability of yield if the JULES-crop model run is started on the sowing date of the crop in that grid box and initialised by the climatological values for that date. This set-up would be simple to reproduce with seasonal forecast forcing that has been bias-corrected to a reanalysis data set, such as those available as part of EUPORIAS, since JULES-crop can be run with this reanalysis data set to produce a climatology of the initialisation variables. Starting the run before or on the sowing date means that the initialisation of crop variables (e.g. height) is trivial since the crop either does not yet exist 
or only exists as a seed. It has also been suggested that the initialisation of impact model runs driven by seasonal forecasts is more critical for some impacts and regions than others; for example, it may be more critical for water resources in cold regions where snow stores are important than for dry land cropping (Falloon et al., 2014a).

It is important to note that while this study provides a practical methodology for driving JULES-crop with seasonal forecasts, given commonly available forcing and initialisation data, there are many aspects of the uncertainty chain that remain to be addressed. For example, once an application has been identified (e.g. a decision threshold based on the yield of a particular crop in a particular region), a thorough validation would need to be performed of the relevant model diagnostic against observational data and against hindcast-driven runs.

This paper is organised as follows. Section 2 describes the JULES-crop model and how it interacts with the other JULES components, Sect. 3 describes the model set-up used for the runs presented in this paper, Sect. 4 presents the results and Sect. 5 draws conclusions from these runs about the model behaviour and sensitivities and how these can inform the design of JULES-crop runs forced with seasonal forecasts.

\section{Model description}

JULES is a process-based model that simulates fluxes of carbon, water, energy and momentum between the land surface and the atmosphere. Sub-grid heterogeneity is represented through tiles of various surface types, such as broadleaf trees, bare soil and C3 grass. As of JULES version 4.0, it includes a crop parametrisation (JULES-crop) which introduces an additional tile for each crop simulated. We refer the reader to Best et al. (2011) and Clark et al. (2011) for a fuller description of JULES and to Osborne et al. (2015) for a description of JULES-crop in particular; here we focus on features that are particularly relevant to this article, such as the influence of temperature on crop growth stage, the influence of soil moisture on photosynthesis and the partitioning of carbon into different parts of the plant.

The status of development of the crop on each tile is parametrised by the crop development index (DVI), which is -2 before sowing, -1 at sowing, 0 at emergence and 1 at flowering. Under normal conditions, harvest occurs at a DVI of 2. The progression between the development stages is determined by crop-specific thermal time parameters, set by the user. For the purposes of this paper, thermal time is an accumulation of effective temperature between one development stage and the next (since we do not include a photoperiod dependence). Effective temperature is defined by

$$
T_{\mathrm{eff}}= \begin{cases}0 & \text { for } \quad T<T_{\mathrm{b}} \\ T-T_{\mathrm{b}} & \text { for } \quad T_{\mathrm{b}} \leq T \leq T_{\mathrm{o}} \\ \left(T_{\mathrm{o}}-T_{\mathrm{b}}\right)\left(1-\frac{T-T_{\mathrm{o}}}{T_{\mathrm{m}}-T_{\mathrm{o}}}\right) & \text { for } \quad T_{\mathrm{o}}<T<T_{\mathrm{m}} \\ 0 & \text { for } \quad T \geq T_{\mathrm{m}}\end{cases}
$$

where $T$ is the air temperature of the tile at that time step and $T_{\mathrm{b}}, T_{\mathrm{o}}$ and $T_{\mathrm{m}}$ are crop-specific cardinal temperatures.

Potential leaf-level photosynthesis (unstressed by water availability and ozone effects) is calculated as the smoothed minimum of three potentially limiting rates, based on Collatz et al. (1991, 1992): (a) the Rubisco-limited rate, which depends on the maximum rate of carboxylation of Rubisco, (b) the light-limited rate and (c) the rate associated with the transport of photosynthetic products for $\mathrm{C} 3$ plants or PEP carboxylase limitation for $\mathrm{C} 4$ plants. The vertical profile of radiation through the canopy can use either the big-leaf approach (following Beer's law) or a multi-layered canopy radiation scheme, which treats the direct and diffuse components of the radiation separately. The latter can optionally include the direct component of the direct beam radiation ("sunflecks"). The potential leaf-level photosynthesis is scaled by a soil water factor $\beta$, to account for soil moisture stress. This factor is 0 when the mean soil moisture content in the root zone $\theta$ is less than or equal to a wilting point concentration $\theta_{\mathrm{w}}, 1$ when $\theta$ is greater than the critical concentration $\theta_{\mathrm{c}}$ and linearly increasing in between (i.e. a slant step function). As of JULES version 4.1, it is possible to irrigate part of each grid box, which involves adding water to the soil until $\beta=1$ during certain times of the year.

NPP is calculated by scaling the leaf-level photosynthesis to the canopy level and subtracting plant maintenance and growth respiration. Crop growth is modelled by integrating NPP over the course of a day and splitting this carbon between the crop root, stem, leaf, harvest and stem reserve carbon pools for that tile ( $C_{\text {root }}, C_{\text {leaf }}, C_{\text {stem }}, C_{\text {harv }}$, and $C_{\text {resv }}$ respectively). The proportion of carbon given to each pool depends on the DVI of the crop and the crop type.

Once the proportion of carbon given to the stem pool drops below 0.01 , carbon from the stem reserve pool is mobilised to the harvest pool, by reducing $C_{\text {resv }}$ by $10 \%$ each day and adding this carbon to the harvest pool. Similarly, once the DVI is above 1.5, carbon from the leaf pool is mobilised to the harvest pool, by reducing $C_{\text {leaf }}$ by $5 \%$ each day and adding this carbon to $C_{\text {harv }}$, to simulate leaf senescence. At harvest, the carbon in the harvest pool becomes yield and each crop carbon pool is reset.

The model does not include a way of calibrating against yield observations (e.g. a yield gap parameter which accounts for the impact of pests, diseases and non-optimal management on the crop yield). Therefore the outputted yield is the water-limited potential yield when irrigation is switched off, and the potential yield when the crop is fully irrigated. 


\section{Experimental set-up}

All runs were performed with JULES 4.2.

\subsection{Control run (control)}

The experimental set-up for the control run follows the global set-up in Osborne et al. (2015). The control run was forced by 6-hourly CRU-NCEPv4 climate data as used by the Global Carbon Project (Le Quéré et al., 2014), regridded to a $n 96$ grid (i.e. grid boxes are 1.875 degrees by 1.25 degrees). The main run was from 1960 to 2009. The initialisation variables were taken from a CRU-NCEP-forced run with the crop model switched off and the model was spun up by repeating the first 10 years five times, before starting the main run, in order to remove the sensitivity to this initialisation. Wheat, soybean, maize and rice were modelled, with the crop parameters listed in Osborne et al. (2015). A multi-layer canopy radiation scheme was used, which accounts for direct/diffuse radiation components including sunflecks (can_ran_mod=5). The crop-sowing dates were taken from Sacks et al. (2010) and extended using nearestneighbour interpolation. The crop tile fractions were taken from Monfreda et al. (2008), and other ancillaries were taken from HadGEM2-ES (Collins et al., 2011; Jones et al., 2011). Irrigation was not switched on.

\subsection{Fully irrigated run (irrig)}

We repeated the control run with irrigation demand switched on, such that, when one of the crops on the grid box had DVI $>-1$, water was added to the top two soil levels until the critical soil moisture content $\theta_{\mathrm{c}}$ was reached, so that the soil water factor $\beta$ was 1 , with no constraint on water availability. The run was initialised and spun up in the same way as the control run.

\subsection{Full disaggregated run (disagg)}

We created daily means and daily temperature ranges from the CRU-NCEPv4 driving data, and we used this to drive a JULES run. The internal JULES disaggregator (described in Williams and Clark, 2014) was used to disaggregate these forcing data to the internal model time step of $1 \mathrm{~h}$. For temperature, this involves adding a sinusoidal diurnal cycle. Precipitation in a day is modelled as occurring in one rainfall event of constant intensity, with a duration that depends on the precipitation type. The run was initialised and spun up in the same way as the control run. All other settings were the same as the control run.

\subsection{Disaggregated runs with some forcing from climatology (sens-*)}

In order to investigate the sensitivity to variability in different parts of the driving data, we created daily climatologies of each driving data variable in the full disaggregated run. For example, for each grid box, the value used for 1 January in the precipitation climatology was the mean over the CRUNCEP precipitation on every 1 January from 1960 to 2009 in that grid box. We then repeated the runs (for 1960 to 2009, as before) with climatological driving data for all variables apart from certain combinations. The combinations we refer to in this paper are shown in Table 1. The run was initialised and spun up in the same way as the control run.

\subsection{Runs initialised from climatology (init)}

We created a climatology for each initialisation variable, for each day of the year, using daily means outputted from the control run and averaging over 1960-2009. The model requires 16 initialisation variables, on multiple model layers or tiles, such as tile surface temperature and moisture in soil layers as a fraction of water content at saturation (see JULES user guide for full list). The model domain was split by sowing date, and we performed a separate run for each sowing date for each crop for each year, initialised by the climatology for that sowing date, without spin up. For example, for maize, we modelled 77 different sowing dates across the globe for 48 years, which involved $77 \times 48$ individual JULES runs. The full 6-hourly driving data were used. Each run lasted 1 year, and the annual yields were concatenated to get a 48-year time series for each crop in each grid box.

\section{Results}

Global time series for each crop were constructed from the model output by first masking any grid boxes which had one or more years in which the crop did not reach a DVI of 1.5 or greater or had a yield less than the seed carbon $0.01 \mathrm{~kg} \mathrm{Cm}^{-2}$ (which we assumed was due to a failure on the part of the model or model settings to represent the crops in this grid box) and then weighting according to grid box size and crop tile fraction. We define a year as 1 January to 31 December (i.e. the model year). In a small fraction of the grid boxes with harvest dates around the end of December/beginning of January, this definition caused issues, as two harvests could fall in one year and none in the next. These points were masked out, as the zero yield appears as a model failure. Osborne et al. (2015) found that maize yield in the control run had the highest correlation with detrended global FAO yield observations out of the four crop types modelled (maize, soybean, rice and wheat); therefore we will explicitly discuss the results for maize only, although we have confirmed that our overall conclusions apply to each of the four crops individually. Results from the other crops are given in the Supplement.

Using daily forcing data and disaggregating rather than using the full 6-hourly data results in a slightly lower mean global yield (10.2 $\mathrm{Mg} \mathrm{ha}^{-1}$ for the disaggregated run, 
Table 1. Combinations of driving variables that are allowed to vary in the sens $-\star$ runs. Each column is a separate run. All driving variables not marked with an " $x$ " are set to their daily climatology.

\begin{tabular}{lccccc}
\hline Name & sens-T & sens-P & sens-TP & sens-TPR & sens-TPW \\
\hline Mean temperature (T) & $\times$ & & $\times$ & $\times$ & $\times$ \\
Precipitation (P) & & $\times$ & $\times$ & $\times$ & $\times$ \\
Downward shortwave radiation (R) & & & & $\times$ & \\
Wind speed (W) & & & & & $\times$ \\
\hline
\end{tabular}

Table 2. Results from the global runs described in Sect. 3. First column is the run name; second column is the mean maize yield (in $\mathrm{Mg}^{-1}$ ); third column is the standard deviation of the annual global yield time series (in $\mathrm{Mgha}^{-1}$ ). The fourth column gives the Pearson correlation coefficient with the global yield in the control run, and the fifth column gives the Pearson correlation coefficient with the global yield in the disagg run. All results have been weighted as described in Sect. 4. These results are presented as scatter plots in Appendix A.

\begin{tabular}{lcccc}
\hline Name & Mean & Standard deviation & Global corr with control & Global corr with disagg \\
\hline control & 10.6 & 0.55 & & \\
irrig & 16.2 & 0.18 & 0.48 & \\
init & 10.3 & 0.48 & 0.91 & \\
disagg & 10.2 & 0.53 & 0.98 & 0.23 \\
\hline sens-T & 10.7 & 0.23 & & 0.87 \\
sens-P & 10.9 & 0.42 & & 0.92 \\
sens-TP & 11.1 & 0.51 & 0.92 \\
sens-TPR & 11.1 & 0.50 & & 0.96 \\
sens-TPW & 10.3 & 0.52 & & \\
\hline
\end{tabular}

compared to $10.6 \mathrm{Mgha}^{-1}$; see Table 2). The global yield time series from the disaggregated run correlates very well with the global yield time series from the control run: the Pearson correlation coefficient is 0.98 . The annual control yield is plotted against the annual disagg yield in Fig. A1, and it shows no obvious deviations from linearity, even at the extremes. Figure 1 (top right) shows the correlation for each grid box, $94 \%$ of which are greater than 0.85 (note that there will be spatial correlation between grid boxes and autocorrelation in the time series for each grid box. Also the Pearson correlation coefficient is not resistant to outliers). It is interesting to note that many of the grid boxes with low correlations are in Brazil, a region where the disaggregator has been seen previously to reproduce the climatology of key variables such as evaporation better than runs driven with 3-hourly data (Williams and Clark, 2014). As discussed in Williams and Clark (2014), since the 3-hourly data are more representative of the underlying driving data than the disaggregated data, this apparent "improvement" with the disaggregator is likely to be result of the extra parameters involved in the disaggregation being tuned to compensate for a bias elsewhere in the model. As a result, the maize yield from the disaggregated run can actually have a higher correlation with FAO country yield data than the control run for Brazil (not shown here). We can therefore conclude that using daily forcing data and disaggregating is a very good approximation to the control run, for the purposes of looking at variability in the maize yield.

Comparing the control run with the fully irrigated run allows us to determine how much of the modelled yield variability is driven by soil moisture variability. Removing the effect of soil moisture stress increases global NPP as expected, which results in considerably higher global mean yields: maize yield rises from 10.6 to $16.2 \mathrm{Mg} \mathrm{ha}^{-1}$ (Table 2). This increase in NPP also has the effect of increasing the number of grid boxes which contribute to the global yield time series, since fewer grid boxes have crops that are harvested prematurely in the model due to lack of growth. Removing soil moisture stress also significantly decreases the (year-to-year) standard deviation for maize yield, which has a global standard deviation of $0.55 \mathrm{Mgha}^{-1}$ in the control run and $0.18 \mathrm{Mg} \mathrm{ha}^{-1}$ in the irrigated run.

We also calculated the Pearson correlation coefficient between the global control run yield and irrigated run yield for each grid box, as shown in Fig. 1, bottom right. There was a high correlation coefficient between the two runs in areas with high rainfall during the model maize-growing season such as Southeast Asia, central Brazil, the northern part of the Amazon Basin and Bangladesh/east India, where we would not expect soil moisture to be a limiting factor in crop growth, even with no irrigation. However, in drier regions, these correlations were much lower, as expected. The percentage of unmasked grid boxes with correlations above 0.85 was just 

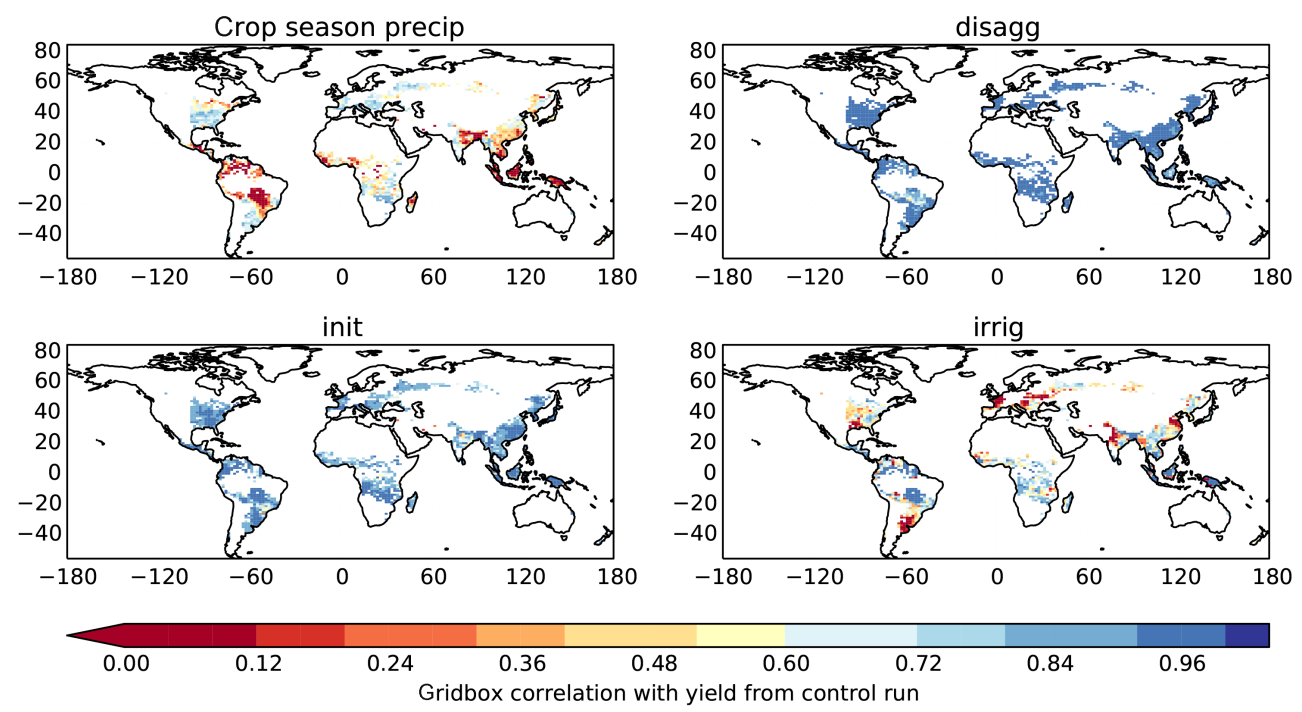

Figure 1. All plots show the correlations with the annual maize yield in the cont rol run for each grid box. Top left: the correlation between yield in control run and crop season precipitation. Top right, bottom left and bottom right: the correlation between yield in control run and yield in the disagg, init and irrig runs respectively.
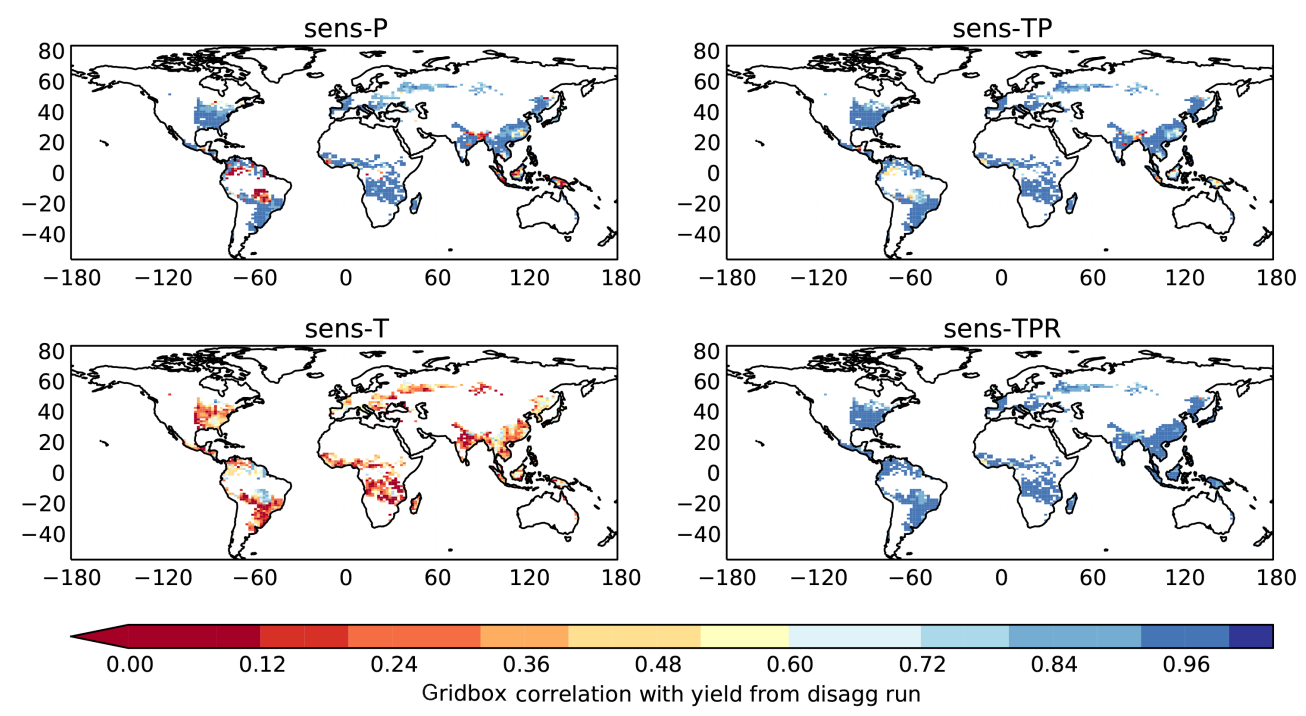

Figure 2. The correlations between the annual maize yield in the disagg run and the annual maize yield from the sens-P (top left), sens-TP (top right), sens-T (bottom left) and sens-TPR (bottom right) runs for each grid box.

$20 \%$ for maize, showing that in most regions soil moisture variability is an import contribution to the yield variability in the control run.

Moving on from soil moisture to precipitation, we constructed a time series for the crop season precipitation by integrating the rainfall between the sowing and harvesting dates for each crop in each grid box. In many regions, this crop season precipitation index correlates reasonably well with the crop yield for the unmasked grid boxes, particularly outside of Southeast Asia, central Brazil, the northern part of the Amazon Basin and Bangladesh/east India, where, as we have already identified, the modelled yield variability does not follow soil moisture variability.

It is therefore interesting to look at how much of the modelled yield variability can be reproduced if the daily precipitation is used to drive the model, while keeping all other variables at their climatological value for each day of the year (sens-P). A priori we can not assume this will be a good approximation to using the full daily driving data (disagg) from the result for the crop season precipitation index above, since, in the control run, the precipitation is not independent of the other driving data. However, Fig. 2 
(top left) shows that the sens-P run does indeed correlate well with the disagg run in areas outside of Southeast Asia, central Brazil, the northern part of the Amazon Basin and Bangladesh/east India. Seventy-four percent of the grid boxes shown have a correlation of 0.85 or more. The correlation between the global yield time series from the sens $-\mathrm{P}$ run and the disagg run is 0.87 . The sens $-\mathrm{P}$ run does have a slightly higher mean global maize yield than the disagg run: $10.9 \mathrm{Mgha}^{-1}$ as compared to $10.2 \mathrm{Mgha}^{-1}$.

If temperature is the only variable allowed to vary between years (i.e. the sens-T run), then the global mean maize yield is $10.7 \mathrm{Mgha}^{-1}$, with standard deviation $0.23 \mathrm{Mg} \mathrm{ha}^{-1}$. This reduction in standard deviation compared to the disagg run is consistent with the reduction in standard deviation seen when the effect of soil moisture was removed (the irrig run). Unsurprisingly, Fig. 2 (bottom left) shows that the sens- $T$ run does not correlate well with the disagg run in areas where the sens-P run had a higher correlation.

If both daily precipitation and daily mean temperature are allowed to vary (sens-PT), the grid box correlations with the disagg run are much more spatially uniform than when either of these variables are varied on their own: in the sens-PT run, $81 \%$ of the grid boxes have a correlation higher than 0.85 (Fig. 2, top right). Many of the areas with low correlations in the sens-P run are much higher in the sens-PT run, such as parts of Brazil, Columbia, Bangladesh and Southeast Asia, although these still remain lower than surrounding regions. The correlation between the global maize yield time series in the sens-TP run and the disagg run is 0.92 . The scatter plot of these yield time series (Fig. A2) shows that the relation between the outputted yield is well approximated by a linear fit. In general, therefore, driving the model with daily precipitation and mean temperature and using climatology for all other driving variables is a good approximation to make when looking at the interannual yield variability across the majority of global maize-growing regions.

In order to improve the approximation further, it may be desirable to additionally allow downward shortwave radiation to vary (sens-PTR) or additionally allow wind speed to vary (sens-PTW). Allowing downward shortwave radiation to vary improves performance (i.e. grid box correlations with the disagg run) in the areas which still have relatively low performance in the sens-PT run, i.e. Brazil, Columbia, Bangladesh and Southeast Asia (Fig. 2, bottom right). Alternatively, allowing wind speed to vary results in a mean global yield that is closer to the mean global of the disagg run (Table 2).

The final remaining question concerns the model initialisation. The set of runs that are initialised on each sowing date with climatology (init) in general reproduce the spatial distribution of yield from the control run. The global yield is generally lower than in the control run in each year, which results in slightly lower mean global yield ( $\left.10.3 \mathrm{Mgha}^{-1}\right)$ compared to the control run $\left(10.6 \mathrm{Mgha}^{-1}\right)$. The correlation between the global maize yield in the init run and the control run is 0.91 (see Fig. A1 for scatter plots), and $70 \%$ of individual grid boxes have a correlation above 0.85 (Fig. 1, bottom left). The correlations are relatively poor in some parts of India, the Congo basin and south/southeastern Brazil. However, outside these areas, initialising on the sowing date has the potential to be a very useful approximation.

\section{Conclusions}

In this article, we have investigated a number of possible approximations that could be made when running JULES-crop:

- use driving data at daily rather than subdaily resolution, and disaggregate internally to the model time step;

- use a subset of daily driving data, and set the rest to a daily climatology.

- initialise with climatology on the crop-sowing date.

Each of these approximations significantly simplifies the use of JULES-crop for seasonal crop yield forecasts, due to the reduction in required driving and initialisation data. With this usage in mind, we have concentrated on the effect of these approximations on the interannual variability of the modelled yield.

Using daily forcing data and disaggregating performs the best out of these approximations, although care should be taken if modelling the Amazon basin, where the precipitation disaggregation parameters may have been tuned to compensate for biases in JULES.

We have shown that, in most regions outside Southeast Asia, central Brazil, the northern part of the Amazon Basin and Bangladesh/east India, the interannual variability of the yield from a JULES-crop run in the control configuration is mainly driven by precipitation, which affects the crop via water availability from the soil, which we have confirmed with a fully irrigated run. As a result, in these regions, it is a good approximation to drive the model with forecast precipitation and leave the other driving data at their climatological values for each day of year. It should be noted that the processes and parameters which govern the response of the crop model to the soil moisture distribution, such as the soil water factor $\beta$ and the root distributions in JULES, are therefore keys areas for future model development. Driving the model with both precipitation and temperature improves the performance in areas with high soil moisture, and some further improvement in these areas can be obtained from the addition of downward shortwave radiation.

Perhaps the most important approximation considered here is initialising with climatology on the sowing date, since obtaining accurate initialisation data on the timescales needed for seasonal forecast runs is a particularly significant 
practical challenge. We have confirmed that this approximation performs well across the majority of maize-growing regions and identified areas where the approximation breaks down.

Taken together, these approximations allow JULES-crop to be driven by seasonal meteorological forecasts where ensembles of bias-corrected daily precipitation and daily tem- perature (and possibly downward shortwave radiation) are available. The reference data set used for the bias correction can be used to generate the climatology of the initialisation variables and the other driving variables. Since these data are widely available, this provides a practical methodology by which to obtain seasonal crop forecasts with JULES-crop. 
Appendix A:

Scatter plots of global yield from model runs
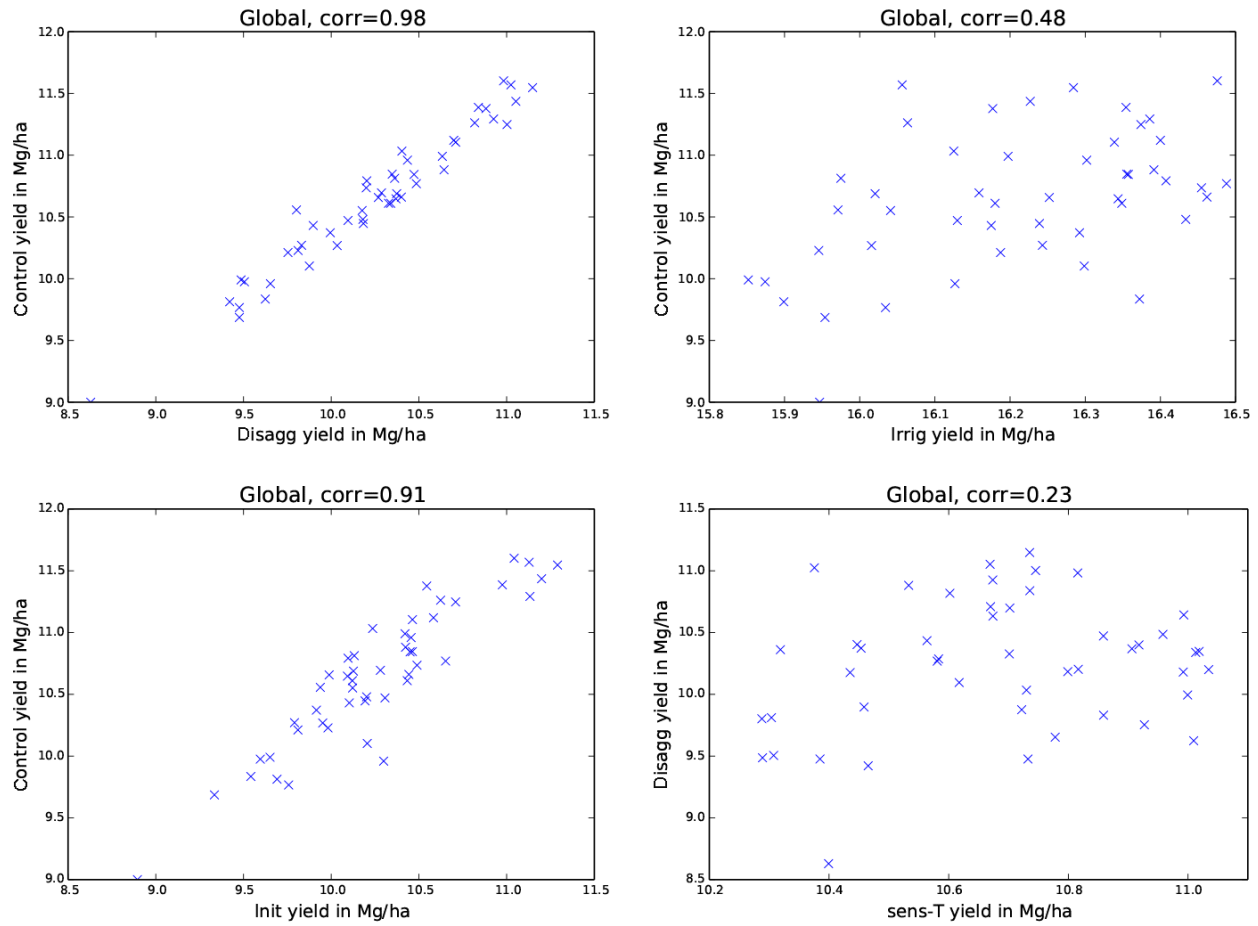

Figure A1. Scatter plots comparing the global mean maize yield from different model runs.
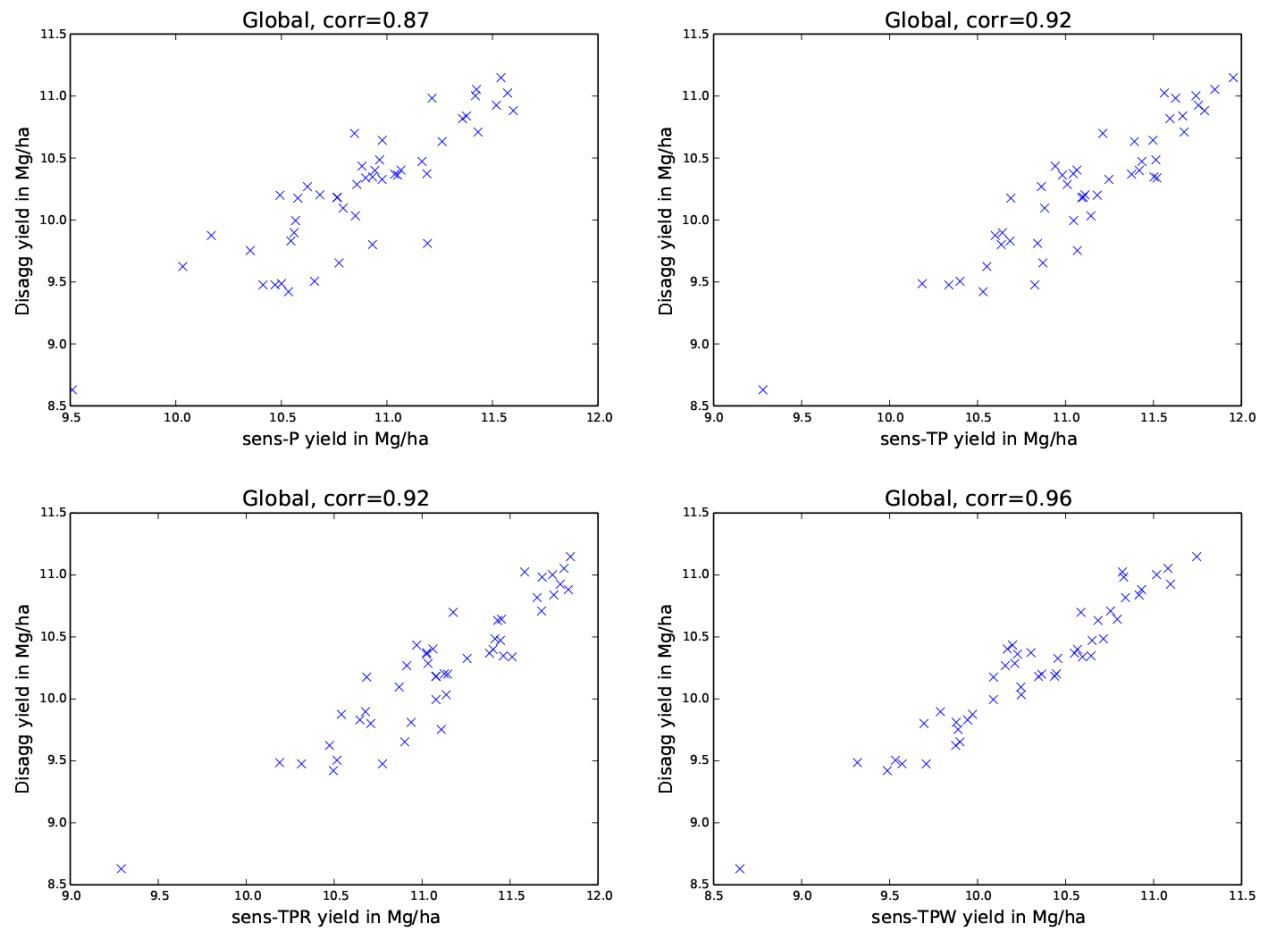

Figure A2. Scatter plots comparing the global mean maize yield from different model runs. 


\section{Copyright statement}

The works published in this journal are distributed under the Creative Commons Attribution 3.0 License. This license does not affect the Crown copyright work, which is re-usable under the Open Government Licence (OGL). The Creative Commons Attribution 3.0 License and the OGL are interoperable and do not conflict with, reduce or limit each other.

() Crown copyright 2015

\section{The Supplement related to this article is available online at doi:10.5194/gmd-8-3987-2015-supplement.}

Acknowledgements. The authors are grateful to Jemma Gornall, Tom Osborne and Camilla Mathison for useful discussions. This article was supported by the Joint DECC-Defra Met Office Hadley Centre Climate Programme (GA01101) and the EUPORIAS project, funded by the European Commission 7th Framework Programme for Research, grant agreement 308291. This work contributed to EUPORIAS D23.5.

Edited by: D. Lawrence

\section{References}

Asseng, S., Ewert, F., Rosenzweig, C., Jones, J. W., Hatfield, J. L., Ruane, A. C., Boote, K. J., Thorburn, P. J., Rotter, R. P., Cammarano, D., Brisson, N., Basso, B., Martre, P., Aggarwal, P. K., Angulo, C., Bertuzzi, P., Biernath, C., Challinor, A. J., Doltra, J., Gayler, S., Goldberg, R., Grant, R., Heng, L., Hooker, J., Hunt, L. A., Ingwersen, J., Izaurralde, R. C., Kersebaum, K. C., Muller, C., Naresh Kumar, S., Nendel, C., O/'Leary, G., Olesen, J. E., Osborne, T. M., Palosuo, T., Priesack, E., Ripoche, D., Semenov, M. A., Shcherbak, I., Steduto, P., Stockle, C., Stratonovitch, P., Streck, T., Supit, I., Tao, F., Travasso, M., Waha, K., Wallach, D., White, J. W., Williams, J. R., and Wolf, J.: Uncertainty in simulating wheat yields under climate change, Nature Clim. Change, 3, 827-832, doi:10.1038/nclimate1916, 2013.

Best, M. J., Pryor, M., Clark, D. B., Rooney, G. G., Essery, R. L. H., Ménard, C. B., Edwards, J. M., Hendry, M. A., Porson, A., Gedney, N., Mercado, L. M., Sitch, S., Blyth, E., Boucher, O., Cox, P. M., Grimmond, C. S. B., and Harding, R. J.: The Joint UK Land Environment Simulator (JULES), model description Part 1: Energy and water fluxes, Geosci. Model Dev., 4, 677-699, doi:10.5194/gmd-4-677-2011, 2011.

Cantelaube, P. and Terres, J.-M.: Seasonal weather forecasts for crop yield modelling in Europe, Tellus A, 57, 476-487, doi:10.1111/j.1600-0870.2005.00125.x, 2005.

Challinor, A. J., Slingo, J. M., Wheeler, T. R., and DoblasReyes, F. J.: Probabilistic simulations of crop yield over western India using the DEMETER seasonal hindcast ensembles, Tellus A, 57, 498-512, doi:10.1111/j.1600-0870.2005.00126.x, 2005.

Challinor, A. J., Watson, J., Lobell, D. B., Howden, S. M., Smith, D. R., and Chhetri, N.: A meta-analysis of crop yield under climate change and adaptation, Nature Clim. Change, 4, 287-291, doi:10.1038/nclimate2153, 2014.

Clark, D. B., Mercado, L. M., Sitch, S., Jones, C. D., Gedney, N., Best, M. J., Pryor, M., Rooney, G. G., Essery, R. L. H., Blyth, E., Boucher, O., Harding, R. J., Huntingford, C., and Cox, P. M.: The Joint UK Land Environment Simulator (JULES), model description - Part 2: Carbon fluxes and vegetation dynamics, Geosci. Model Dev., 4, 701-722, doi:10.5194/gmd-4-701-2011, 2011.

Coelho, C. A. S. and Costa, S. M. S.: Challenges for integrating seasonal climate forecasts in user applications, Curr. Opin. Environ. Sustain., 2, 317-325, doi:10.1016/j.cosust.2010.09.002, 2010.

Collatz, Ball, Grivet, C., and Berry, J. A.: Physiological and environmental regulation of stomatal conductance, photosynthesis and transpiration: a model that includes a laminar boundary layer, Agricultural and Forest Meteorology, 54, 107-136, doi:10.1016/0168-1923(91)90002-8, 1991.

Collatz, G. J., Ribas-Carbo, M., and Berry, J. A.: Coupled Photosynthesis-Stomatal Conductance Model for Leaves of C4 Plants, Aust. J. Plant Physiol., 19, 519-538, 1992.

Collins, W. J., Bellouin, N., Doutriaux-Boucher, M., Gedney, N., Halloran, P., Hinton, T., Hughes, J., Jones, C. D., Joshi, M., Liddicoat, S., Martin, G., O'Connor, F., Rae, J., Senior, C., Sitch, S., Totterdell, I., Wiltshire, A., and Woodward, S.: Development and evaluation of an Earth-System model - HadGEM2, Geosci. Model Dev., 4, 1051-1075, doi:10.5194/gmd-4-10512011, 2011.

Cosgrove, B. A., Lohmann, D., Mitchell, K. E., Houser, P. R., Wood, E. F., Schaake, J. C., Robock, A., Sheffield, J., Duan, Q., Luo, L., Higgins, R. W., Pinker, R. T., and Tarpley, J. D.: Land surface model spin-up behavior in the North American Land Data Assimilation System (NLDAS), J. Geophys. Res., 108, 8845, doi:10.1029/2002jd003316, 2003.

Dessai, S. and Bruno Soares, M.: Systematic literature review on the use of seasonal to decadal climate and climate impacts predictions across European sectors, Tech. Rep. D12.1, University of Leeds, available at: http://www.euporias.eu/system/files/D12. 1_Final.pdf (last access: 17 June 2015), 2013.

Falloon, P., Fereday, D., Stringer, N., Williams, K., Gornall, J., Wallace, E., Eade, R., Brookshaw, A., Camp, J., Betts, R., Dankers, R., Nicklin, K., Vellinga, M., Graham, R., Arribas, A., and MacLachlan, C.: Assessing skill for impacts in seasonal to decadal climate forecasts, J. Geol. Geosci., 2, e111, doi:10.4172/2329-6755.1000e111, 2013.

Falloon, P., Buontempo, C., Ceron, J. P., Dubus, L., Greuell, W., Hutjes, R., Jönsson, A. M., Lowe, R., Manzanas, R. G., San Martin, M. T., Newton, P., Nicklin, K., Pechlivanidis, I., Pouget, L., Supit, I., and Williams, K.: Report on initialisation of impacts models for seasonal predictions, Tech. Rep. D23.3, EUPORIAS, available at: http://www.euporias.eu/system/files/D23.3_ Final.pdf (last access: 17 June 2015), 2014a.

Falloon, P., Challinor, A., Dessai, S., Hoang, L., Johnson, J., and Koehler, A.-K.: Ensembles and uncertainty in climate change impacts, Front. Environ. Sci., 2, 33, doi:10.3389/fenvs.2014.00033, 2014b.

Hansen, J. W., Challinor, A., Ines, A., Wheeler, T., and Moron, V.: Translating climate forecasts into agricultural terms: advances and challenges, Clim. Res., 33, 27-41, doi:10.3354/cr033027, 2006. 
Hansen, J. W., Mason, S. J., Sun, L., and Tall, A.: Review Of seasonal climate forecasting for agriculture in sub-Saharan Africa, Exp. Agr., 47, 205-240, doi:10.1017/s0014479710000876, 2011.

Hewitt, C., Buontempo, C., and Newton, P.: Using climate predictions to better serve society's needs, EOS T. Am. Geophys. Un., 94, 105-107, doi:10.1002/2013eo110002, 2013.

Iizumi, T., Sakuma, H., Yokozawa, M., Luo, J.-J., Challinor, A. J., Brown, M. E., Sakurai, G., and Yamagata, T.: Prediction of seasonal climate-induced variations in global food production, Nature Clim. Change, 3, 904-908, doi:10.1038/nclimate1945, 2013.

Iizumi, T., Yokozawa, M., Sakurai, G., Travasso, M. I., Romanenkov, V., Oettli, P., Newby, T., Ishigooka, Y., and Furuya, J.: Historical changes in global yields: major cereal and legume crops from 1982 to 2006, Global Ecol. Biogeogr., 23, 346-357, doi:10.1111/geb.12120, 2014.

Jones, C. D., Hughes, J. K., Bellouin, N., Hardiman, S. C., Jones, G. S., Knight, J., Liddicoat, S., O’Connor, F. M., Andres, R. J., Bell, C., Boo, K.-O., Bozzo, A., Butchart, N., Cadule, P., Corbin, K. D., Doutriaux-Boucher, M., Friedlingstein, P., Gornall, J., Gray, L., Halloran, P. R., Hurtt, G., Ingram, W. J., Lamarque, J.-F., Law, R. M., Meinshausen, M., Osprey, S., Palin, E. J., Parsons Chini, L., Raddatz, T., Sanderson, M. G., Sellar, A. A., Schurer, A., Valdes, P., Wood, N., Woodward, S., Yoshioka, M., and Zerroukat, M.: The HadGEM2-ES implementation of CMIP5 centennial simulations, Geosci. Model Dev., 4, 543-570, doi:10.5194/gmd-4-543-2011, 2011.

Le Quéré, C., Peters, G. P., Andres, R. J., Andrew, R. M., Boden, T. A., Ciais, P., Friedlingstein, P., Houghton, R. A., Marland, G., Moriarty, R., Sitch, S., Tans, P., Arneth, A., Arvanitis, A., Bakker, D. C. E., Bopp, L., Canadell, J. G., Chini, L. P., Doney, S. C., Harper, A., Harris, I., House, J. I., Jain, A. K., Jones, S. D., Kato, E., Keeling, R. F., Klein Goldewijk, K., Körtzinger, A., Koven, C., Lefèvre, N., Maignan, F., Omar, A., Ono, T., Park, G.-H., Pfeil, B., Poulter, B., Raupach, M. R., Regnier, P., Rödenbeck, C., Saito, S., Schwinger, J., Segschneider, J., Stocker, B. D., Takahashi, T., Tilbrook, B., van Heuven, S., Viovy, N., Wanninkhof, R., Wiltshire, A., and Zaehle, S.: Global carbon budget 2013, Earth Syst. Sci. Data, 6, 235-263, doi:10.5194/essd-6-2352014, 2014.

MacLachlan, C., Arribas, A., Peterson, K. A., Maidens, A., Fereday, D., Scaife, A. A., Gordon, M., Vellinga, M., Williams, A., Comer, R. E., Camp, J., Xavier, P., and Madec, G.: Global Seasonal forecast system version 5 (GloSea5): a high-resolution seasonal forecast system, Q. J. Roy. Meteorol. Soc., 141, 10721084, doi:10.1002/qj.2396, 2015.

Manzanas, R., Frías, M. D., Cofiño, A. S., and Gutiérrez, J. M.: Validation of 40 year multimodel seasonal precipitation forecasts: the role of ENSO on the global skill, J. Geophys. Res.-Atmos., 119, 1708-1719, doi:10.1002/2013jd020680, 2014.
Marletto, V., Ventura, F., Fontana, G., and Tomei, F.: Wheat growth simulation and yield prediction with seasonal forecasts and a numerical model, Agr. Forest Meteorol., 147, 71-79, doi:10.1016/j.agrformet.2007.07.003, 2007.

Mishra, A., Hansen, J. W., Dingkuhn, M., Baron, C., Traoré, S. B., Ndiaye, O., and Ward, M. N.: Sorghum yield prediction from seasonal rainfall forecasts in Burkina Faso, Agr. Forest Meteorol., 148, 1798-1814, doi:10.1016/j.agrformet.2008.06.007, 2008.

Molteni, F., Stockdale, T., Balmaseda, M., Balsamo, G., Buizza, R., Ferranti, L., Magnusson, L., Mogensen, K., Palmer, T., and Vitart, F.: The new ECMWF seasonalforecast system (System 4), Tech. Rep. 656, ECMWF, available at: http://old.ecmwf.int/publications/library/ecpublications/_pdf/ tm/601-700/tm656.pdf (last access: 17 June 2015), 2011.

Monfreda, C., Ramankutty, N., and Foley, J. A.: Farming the planet: 2. Geographic distribution of crop areas, yields, physiological types, and net primary production in the year 2000, Global Biogeochem. Cy., 22, GB1022, doi:10.1029/2007gb002947, 2008.

Nicklin, K. J., Challinor, A., and Tompkins, A.: The use of seasonal forecasts in a crop failure early warning system for West Africa, AGU Fall Meeting Abstracts, A1007+, available at: http: //adsabs.harvard.edu/abs/2011AGUFMGC31A1007N (last access: 17 June 2015), 2011.

Osborne, T., Gornall, J., Hooker, J., Williams, K., Wiltshire, A., Betts, R., and Wheeler, T.: JULES-crop: a parametrisation of crops in the Joint UK Land Environment Simulator, Geosci. Model Dev., 8, 1139-1155, doi:10.5194/gmd-8-11392015, 2015.

Palmer, T. N., Doblas-Reyes, F. J., Hagedorn, R., Alessandri, A., Gualdi, S., Andersen, U., Feddersen, H., Cantelaube, P., Terres, J. M., Davey, M., Graham, R., Délécluse, P., Lazar, A., Déqué, M., Guérémy, J. F., Díez, E., Orfila, B., Hoshen, M., Morse, A. P., Keenlyside, N., Latif, M., Maisonnave, E., Rogel, P., Marletto, V., and Thomson, M. C.: Development of a European Multimodel Ensemble System for Seasonal-tointerannual Prediction (DEMETER), B. Am. Meteorol. Soc., 85, 853-872, doi:10.1175/bams-85-6-853, 2004.

Sacks, W. J., Deryng, D., Foley, J. A., and Ramankutty, N.: Crop planting dates: an analysis of global patterns, Global Ecol. Biogeogr., 19, 607-620, doi:10.1111/j.1466-8238.2010.00551.x, 2010.

Watson, J. and Challinor, A.: The relative importance of rainfall, temperature and yield data for a regionalscale crop model, Agr. Forest Meteorol., 170, 47-57, doi:10.1016/j.agrformet.2012.08.001, 2013.

Watson, J., Challinor, A., Fricker, T., and Ferro, C.: Comparing the effects of calibration and climate errors on a statistical crop model and a process-based crop model, Climatic Change, 132, 1-17, doi:10.1007/s10584-014-1264-3, 2014.

Williams, K. and Clark, D.: Disaggregation of daily data in JULES, Tech. Rep. 96, Met Office Hadley Centre, available at: http:// www.metoffice.gov.uk/media/pdf/2/j/HCTN96.pdf (last access: 17 June 2015), 2014. 